\title{
Adaptations in teaching modalities for medical undergraduates in response to coronavirus disease 2019 at a single teaching institute in India
}

\author{
Swati Sharma, Avik Ray and Balakrishnan Sadasivam \\ Department of Pharmacology, All India Institute of Medical Sciences Bhopal, Bhopal, India
}

What started as a pneumonia of unknown cause in Wuhan, with the first case reported to World Health Organization (WHO) on 31 December, 2019 [1], has by now taken its toll on 4.94 lac people across the globe who have lost their lives to this pandemic [2]. It has not only affected the lives of the 9.8 million people who have tested positive for the dreadful virus [2], severe acute respiratory syndrome coronavirus 2, but of necessarily every living being on this planet. Health care workers are working tirelessly to treat those suffering from coronavirus disease 2019 (COVID-19) and many have themselves fallen prey to it and lost their lives. Because of this current scenario, the process of readying new doctors, to be able to cope up with the ongoing situation as well as with the aftermath of the pandemic, has suffered a huge blow. Medical education, which can be learned in its true sense primarily by hands-on experience, has been lagging behind because of the risks involved.

In India, a nationwide lockdown was announced on 24
March, 2020 [3]. Educational institutes across the country had anticipated the government's move quite early on and had got their campuses vacated, so students could safely reach their respective homes before the situation got any worse. Most of the medical institutes, however, took this decision a bit later, perhaps trying to turn this "once in a lifetime opportunity" of facing a pandemic into a learning experience for the future doctors. Although, the increasing outreach of the virus did not allow this to go on for long and medical students too, had to be sent to their homes. The reason behind this decision was not just the concern for their safety, it was also the prediction of the increasing COVID patient-load in which case, the hostels would be converted into make-shift wards or quarantine facilities for health care workers as per requirement.

At All India Institute of Medical Sciences (AIIMS) Bhopal, a medical institute of national importance in central India, soon after the closure of medical school, official orders were issued to conduct classes online as a
Received: June 27, 2020 • Revised: July 31, 2020 • Accepted: August 24, 2020 Corresponding Author: Swati Sharma (https://orcid.org/0000-0003-3182-5331) Department of Pharmacology, All India Institute of Medical Sciences Bhopal, Bhopal 462020, Madhya Pradesh, India

Tel: +91.7976549550 Fax: +91.0755.2672355 email: swati.jr2019@aiimsbhopal.edu.in
Korean J Med Educ 2020 Dec; 32(4): 291-295.

https://doi.org/10.3946/kjme.2020.177

eISSN: 2005-7288

(C) The Korean Society of Medical Education. All rights reserved. This is an open-access article distributed under the terms of the Creative Commons Attribution Non-Commercial License (http:// creativecommons.org/licenses/by-nc/3.0/), which permits unrestricted non-commercial use, distribution, and reproduction in any medium, provided the original work is properly cited. 
stop-gap arrangement, so that medical students don't miss out on the theoretical knowledge at least. Because of platforms like Google Meet, it has been possible for students to not only be in touch with their studies, but also prevent them from falling prey to boredom and depression by keeping them busy and engaged. Despite there being many benefits that technology endows upon us, there are many associated problems that go hand-in-hand.

Most of the professors, as well as residents, have been assigned some or the other task related to COVID, be it direct involvement in the screening and treatment of patients or indirect involvement in aspects like contact tracing, telemedicine, and so forth. Those not working at COVID front are assigned duties in non-COVID areas of the institute for catering to the routine and emergency patients who visit the hospital for non-COVID reasons. This leaves very limited number of people available for taking classes and imparting knowledge.

There still are many places in our country that don't have access to the Internet at all. The 2017-2018 National Sample Survey found that approximately 24\% of the households in India have an internet access which shows that we are probably not yet ready to digitalize the education system completely [4]. Besides, smartphones and laptops are must-haves in order to be able to attend online classes and all this conundrum of arranging online classes becomes futile in case a student doesn't have either internet or a "smart" device. An unfortunate incident was in news recently, where a school girl committed suicide because she missed an online class [5]. This emphasizes the need to make the prerequisite commodities available to all students who are supposed to be benefitted, so that any undue stress and pressure of falling behind can be off-loaded from those unable to access the classes otherwise.

Since online teaching depends a lot on the connec- tivity and availability of uninterrupted internet, it poses a lot of unique challenges unlike the traditional chalktalk method of imparting knowledge. Poor network, frequent power-cuts, and lack of high-speed internet connection are some of the major factors which might hinder our efforts to scale-up tele-education just yet. However, we need to come up with solutions to ensure inclusive e-learning for the medical undergraduates in the country while tackling the digital divide. Opensource digital learning platforms and learning management software need to be incorporated to ensure continuity of education even at times of lockdowns. These might also be made a part of the regular Bachelor of Medicine and Bachelor of Surgery (MBBS; the medical undergraduate degree in India) curriculum wherein the students can interact with the faculty members via some tele-education platform, especially for clearance of doubts, and enroll themselves in some online courses which might help them earn some microcredits.

The ease of holding interactive sessions through use of webcams and microphones is probably one of the biggest achievements associated with these online classes. Cold calls in live classroom-based teaching often find students inattentive to the ongoing lectures and demonstrations. This is mainly due to the fact that the classrooms are usually quite large and the number of students attending it is more than what a single teacher could manage effectively. Further, students often feel intimidated when asked questions in classes. Digital classes allow the teachers to look at everyone attending it quite easily by a quick glance at the computer screen and it would be quite interesting to keep a note on how the behavior of the students is changing with the changing mode of delivery of education. It would also be insightful to understand the perspectives of the teachers and gather their feedbacks. 
Fig. 1. Line Graphs Showing Attendance Percentage over 3 Months

(A)

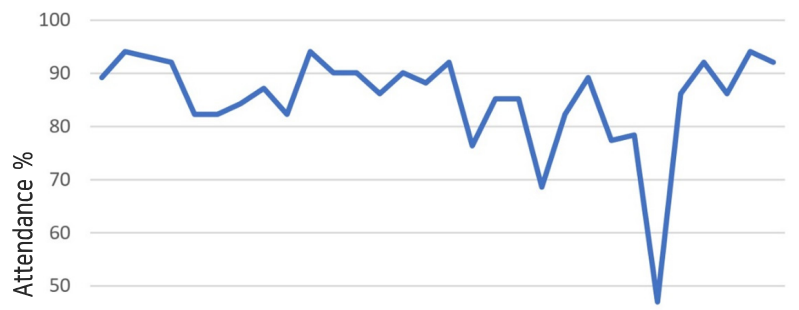

40

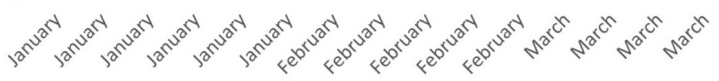

Month
(B)

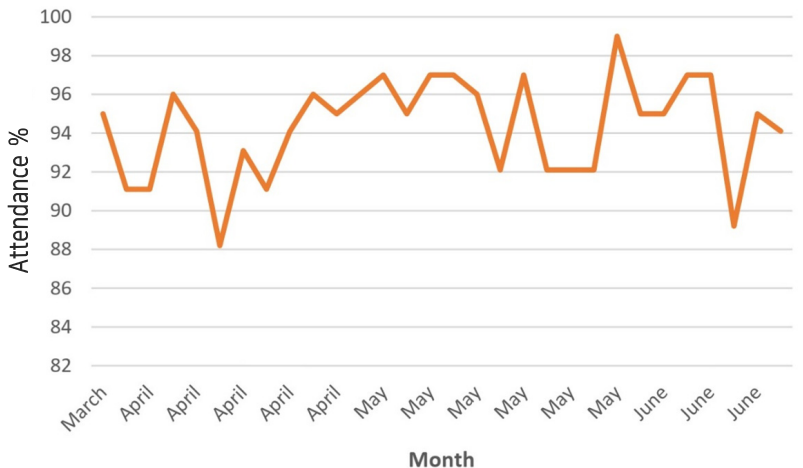

Month

(A) Real-time classroom attendance percentage. (B) Digital classroom attendance percentage. The trend is visibly higher for digital classes.

In the Department of Pharmacology at AIIMS Bhopal, faculty members have been taking online classes on Google Classroom for second-year medical undergraduates over the last 4 months. These include theory classes, tutorials on topics like prescription writing covering a broad range of clinical case-based scenarios, as well as practical classes using a simulation software, ExPharm Pro, wherein students learn the effect of various drugs on virtual animal tissues. Ever since the beginning of online classroom, the teachers have noted a gross difference in the attendance of students compared to that in real-time classes. In order to confirm this observation, we conducted statistical analyses of the attendance data, for both real-time and digital classes. The faculty members upload their classes in the form of power point presentations with voiceovers on Google Classroom (link shared with students through email) and the students mention their names and roll numbers in the comments section once they access those recorded presentations. The attendance data is extracted from there and is entered in to a register which contains the in-person attendance information as well. Tutorials and practical classes are conducted as live classes on Google Meet, allowing interaction between teachers and students, who participate by raising their doubts to the teachers and by answering questions that are addressed to them collectively as well as individually. Here, students attend to their roll call and attendance is then entered in to the register. Based on the data for 30 classes for both (mid-January to mid-March for real-time and mid-March to mid-June for digital), overall, the trend of attendance percentage was higher for digital classroom as compared to real-time (Fig. 1A, B). Further, the mean attendance percentage for digital classroom $(94.32 \% \pm 2.59 \%)$ was higher as compared to real-time classroom mean attendance percentage $(85.27 \% \pm 9.40 \%)$; a paired sample Student t-test indicated a statistically significant difference between these two $(\mathrm{p}<0.001)$. Interestingly, the variance for digital classroom attendance was much lower than real-time classroom showing the higher consistency of students attending the digital classroom which might lead to a better learning experience. This could be because of the flexibility of being able to attend classes per their convenience in the comfort of their homes. Besides, feedback was obtained from students (as was routinely done even before lockdown in real-time classes) by sending them a link to an online form via e-mail (questions asked as shown in Table 1, along with the response percentages). Eighty-six responses were obtained out of a total of 102 students. It is clear from the students' responses that they opted for real-time 
Table 1. The Questions Asked and the Corresponding Response Percentages

\begin{tabular}{|c|c|c|c|}
\hline Serial no. & Question & Options & Percentage response \\
\hline \multirow[t]{3}{*}{1.} & What should be the duration of digital classes? & $30 \mathrm{~min}$ & 54.7 \\
\hline & & $45 \mathrm{~min}$ & 41.9 \\
\hline & & $60 \mathrm{~min}$ & 3.4 \\
\hline \multirow[t]{3}{*}{2.} & What should be the duration of real-time classes? & $30 \mathrm{~min}$ & 30.2 \\
\hline & & $45 \mathrm{~min}$ & 44.2 \\
\hline & & $60 \mathrm{~min}$ & 25.6 \\
\hline \multirow[t]{3}{*}{3.} & Which mode of class is better according to you? & Real-time class & 60.5 \\
\hline & & Digital class & 25.6 \\
\hline & & Both & 14 \\
\hline \multirow[t]{3}{*}{4.} & How is your interaction with the teacher in digital class compared to real-time & Better & 12.8 \\
\hline & class? & Same & 50 \\
\hline & & Worse & 37.2 \\
\hline \multirow[t]{3}{*}{5.} & Are you less afraid of answering a question in digital class compared to & Yes, I am less afraid & 38.4 \\
\hline & in real-time class? & No, I am more afraid & 23.3 \\
\hline & & It's the same for both & 38.4 \\
\hline \multirow[t]{3}{*}{6.} & Do you think digital classes are preventing you from falling behind in your & Yes & 39.5 \\
\hline & curriculum? & No & 34.9 \\
\hline & & May be & 25.6 \\
\hline
\end{tabular}

classes as the better modality of class compared to digital classes. However, as mentioned earlier, the attendance shows a contrasting picture altogether. This goes on to show that it might take a bit more time for students to adapt to this change.

The national telemedicine guideline, which has been formulated and formally released on March 25, 2020, has given us a hint towards the future of digital medicine in India [6]. Telehealth and telemedicine should be included as a part of the MBBS curriculum so that the future doctors could be well versed with its functioning. We should consider starting specialized postgraduation courses on telemedicine so that it could be incorporated as a part of the regular medical practice. This would enable us to strengthen the system, gain trust of the patients as a reliable consultation mode and be well prepared for the next public health emergency. In a nation where the doctor-to-patient ratio is highly skewed, with the value being nowhere close to the WHO recommended 1:1,000, this might really come in handy to treat the masses and put a step forward towards improving accessibility of affordable healthcare. Hence, training young medical students in e-learning might be a good way to get them accustomed to the digital environment.

We can't expect digital learning to completely replace physical teaching ever in medicine. It has allowed students to adapt to the unresolved situation, but only for so long. The students need to visit the wards and the operation theatres for hands-on training without which they really cannot learn the basics. Hence, even though we are able to impart theoretical knowledge to them through the online classes, the syllabus coverage for practical portions is totally hampered. In the near future, we might probably be able to come up with some disruptive technology which would allow even the practical classes to be organized smoothly over the digital platforms. But it is hard to say that e-learning for MBBS undergraduates would be a sustainable solution. It would also be possible to decide on the future of digital learning by conducting exams as soon as it is possible to, so that this new way of teaching and learning can be put to test. By comparing how well the students fare in exams after digital classes versus what they used to, after 
real-time classes, we might be able to judge the merits of this new method of teaching.

Despite the lockdown being lifted, the precariousness of the situation has prevented the government to allow for re-opening of colleges and universities yet. Semester exams that were supposed to have been conducted at our institute have been postponed till further notice. This creates a sense of uncertainty in the minds of students about their future. Virtual classes are perhaps the only mode of rescue that can be relied on and also the "new normal" for students for now.

Similar experiences have been reported in different parts of the world [7,8], highlighting the global impact that the pandemic has had on medical education.

\section{ORCID:}

Swati Sharma: https://orcid.org/0000-0003-3182-5331;

Avik Ray: https://orcid.org/0000-0002-0047-7453;

Balakrishnan Sadasivam: https://orcid.org/0000-0002-9125-8132

Acknowledgements: The authors are thankful to Dr. Saurav Misra, senior resident in the Department of Pharmacology at AIIMS Bhopal, who helped in collecting feedback from students.

Funding: No funding was obtained for this study.

Conflicts of interest: No potential conflict of interest relevant to this article was reported.

Author contributions: Conception of idea and critical revision of the article: BS; data collection, drafting and completion of the article: SS; data analysis and drafting of the article: AR; and review and final approval: all authors.

\section{References}

1. World Health Organization. Rolling updates on coronavirus disease (COVID-19). https://www.who.int/emergencies/d iseases/novel-coronavirus-2019/events-as-they-happen. Published June 2020. Accessed June 27, 2020.

2. Johns Hopkins University. COVID-19 Dashboard by the Center for Systems Science and Engineering at Johns Hopkins University. https://coronavirus.jhu.edu/map.htm 1. Accessed June 27, 2020.

3. The New York Times. India, day 1: world's largest coronavirus lockdown begins. https://www.nytimes.co m/2020/03/25/world/asia/india-lockdown-coronavirus.ht ml. Published March 2020. Accessed June 27, 2020.

4. Ministry of Statistics and Programme Implementation, Government of India. Key indicators of household social consumption on education in India. http://mospi.nic.in/si tes/default/files/publication_reports/KI_Education_75th_ Final.pdf. Published November 2019. Accessed June 27, 2020.

5. NDTV. Unable to join online classes, Kerala schoolgirl commits suicide: cops. https://www.ndtv.com/india-news/ coronavirus-kerala-girl-cant-attend-online-classes-amid-lo ckdown-commits-suicide-2239318. Published June 2020. Accessed June 27, 2020.

6. Ministry of Health and Family Welfare, Government of India. Telemedicine practice guidelines: enabling registered medical practitioners to provide healthcare using telemedicine. https://www.mohfw.gov.in/pdf/Telemedicine. pdf. Published March 2020. Accessed June 27, 2020.

7. Sia $\mathrm{CH}$, Tan BY, Ooi SB. Impact of the coronavirus disease 2019 pandemic on postgraduate medical education in a Singaporean academic medical institution. Korean J Med Educ. 2020;32(2):97-100.

8. Park J, Rhim HC. Consequences of coronavirus disease 2019 on international medical graduates and students applying to residencies in the United States. Korean J Med Educ. 2020;32(2):91-95. 